\title{
The Effect of Psychodrama on the Empathy and Social Anxiety Level in Adolescents
}

\author{
Psikodramanin Ergenlerde Empati ve Sosyal Kayg Düzeyine Etkisi
}

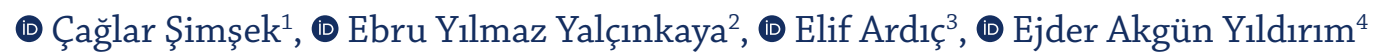

${ }^{1}$ Taksim Training and Research Hospital, Patient Rights Unit, Istanbul, Turkey

${ }^{2}$ University of Health Sciences Turkey, Gaziosmanpaşa Taksim Training and Research Hospital, Clinic of Physical Medicine and Rehabilitation, Istanbul, Turkey ${ }^{3}$ Marmara University Faculty of Health Scienes, Department of Psychiatric Nursing, Istanbul, Turkey

${ }^{4}$ University of Health Sciences Turkey, Bakırköy Prof. Dr. Mazhar Osman Mental Health and Diseases Training and Research Hospital, Psychotherapy Training and Treatment Center, Istanbul, Turkey

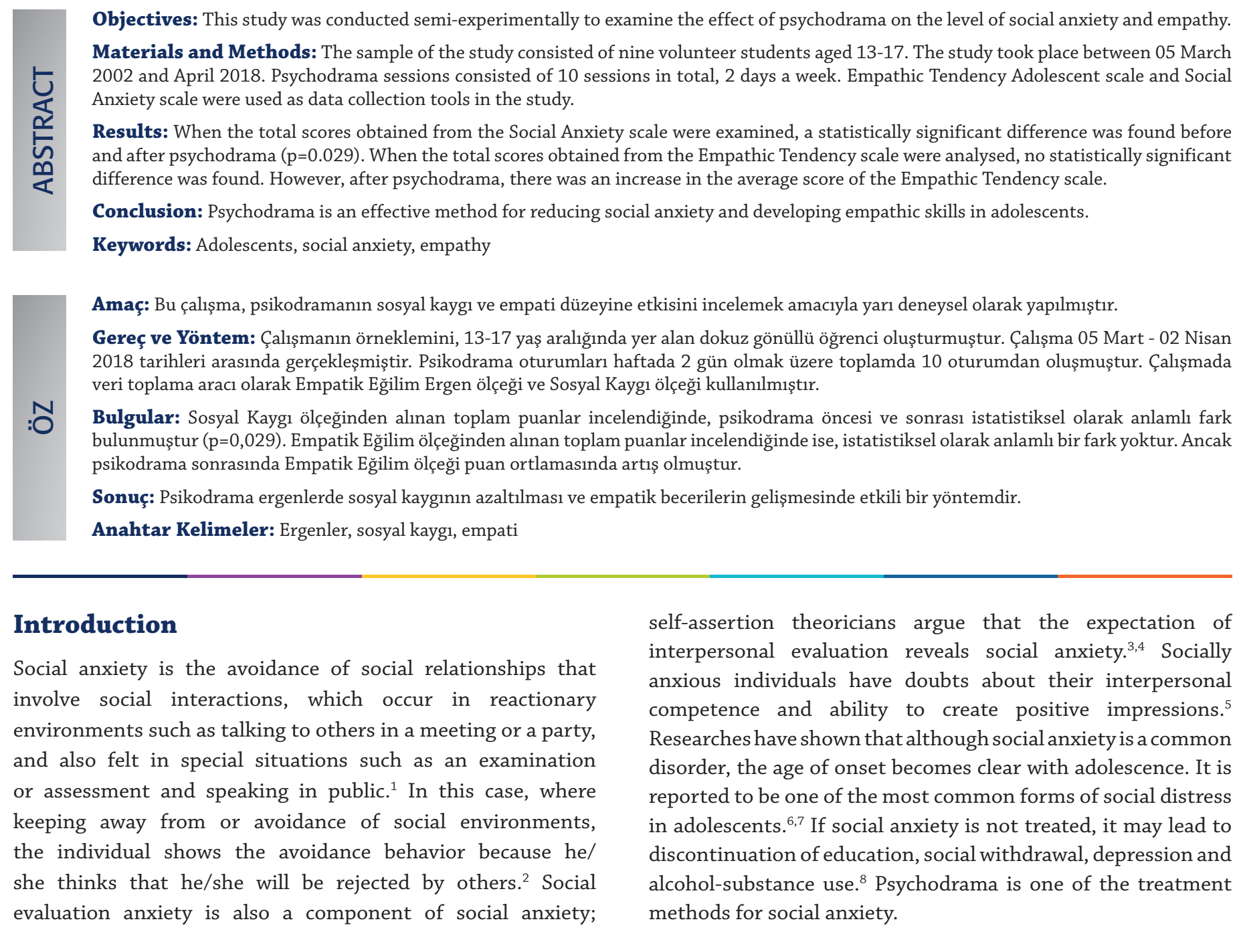


Psychodrama is a therapeutic method that aims to create insight and awareness by providing alternative solutions to the problems of individuals, groups and society depending on their emotions, thoughts and some disturbing events in their lives. ${ }^{9,10}$ It is a method of psychotherapeutic and sociotherapeutic action which is mostly applied in groups and is a method of psychotherapy in which individuals rehearse their lives. ${ }^{11}$ As group therapy may be beneficial in the treatment of psychiatric diseases seen in adolescents, so there is a tendency to create more group activities in them. ${ }^{12}$ In addition to the benefit of being in the peer group due to the age group characteristics, psychodrama applications also benefit in the realization of emotions, acquiring new social skills and developing direct self-confrontation and empathy skills in adolescents. ${ }^{13,14}$

Empathy, which forms the basis of communication, has gained much importance today and has an essential role in interpersonal relations. ${ }^{15}$ It is generally regarded as a multidimensional structure that includes cognitive as well as affective processes, including understanding, perceiving and sharing the emotional states of others. ${ }^{16}$ It is the ability of the person to see his/her own point of view by putting himself/herself in the place of the other person in terms of emotion, thought and behavior, while respecting his/ her point of view and looking at the events from his/her own point of view and acting in common. ${ }^{17}$ Dökmen $^{18}$ also states that when an individual understands the feelings and ideas of others with empathy and conveys them to the other party, it is also regarded as a component of empathy. If adolescents have an empathic tendency, they will look at the events from different angles and put himself/herself in another's position and resolves the conflict in a more positive way. Resolution of conflicts with empathy in adolescents can have beneficial consequences. Thus, it is important that adolescents have empathic tendency, and they should use it in many areas such as resolution of conflicts.

Psychodrama studies conducted among individuals with social anxiety are limited. Uneri et al. ${ }^{19}$ indicated that no psychodrama studies on adolescents had been conducted up to that year. In addition, the situations experienced during adolescence leave important traces in the future lives of individuals. This study aims to determine the effect of psychodrama on the level of empathy and social anxiety in adolescents. The results of the study will contribute to the literature in this field.

\section{Materials and Methods}

In this study, a semi-experimental and special-purpose sampling method was used. The study took place between 19 February and 19 March. The sample of the study consisted of 8-13 yearold children hospitalized in the Physical Therapy Clinic of a Training and Research Hospital in the European side of Istanbul who had applied for reading and playing games in this clinic. The study group consisted of 9 volunteer students ( 4 boys and 5 girls) aged 13-17 years. Preliminary interviews were conducted with the students who applied to the hospital within the scope of the social responsibility project of a secondary education institution. The students who stated their anxiety of how to interact with paediatric patients as a result of the interview were invited to the psychodrama study. The psychodrama study was carried out by the expert psychiatric nurse who completed the psychodrama training at the Abdülkadir Özbek Psychodrama Institute. During the study, 10 sessions of psychodrama was conducted with the supervision of Abdülkadir Özbek Psychodrama Institute trainer, 2 days a week for 2 hours in the hospital library between March and April 2018. In the study, KaSi Empathic Tendency Adolescent scale and Social Anxiety scale for adolescents (SAS-A) were used for data collection. Statistical evaluation was made by applying pre- and post-test.

\section{Inclusion Criteria}

- Applying to the hospital within the scope of the social responsibility project

- Being a secondary school student

- Not having a psychiatric diagnosis

- Being a volunteer

- The parents' consent

\section{Exclusion Criteria}

- Being a university student

- Being a primary school student

\section{Psychodrama Sessions}

A psychodrama session consists of three main phases: warm-up, play stage and group meeting.

Warm-up stage: A psychodrama session begins with the warm-up phase, which aims to prepare the group members and the manager for the role, topic and current situation. Warm-up allows members to increase their spontaneity and break the resistance of the group. At this stage, it is decided how the group will work and who will be the protagonist. ${ }^{20}$

Play stage: This stage is the action stage that includes the implementation of the decisions made during the warm-up phase. At this stage, the manager applies basic techniques of psychodrama and some auxiliary techniques.

Group meeting: Group meeting is the stage where the group members share th feedback about their role at the end of the game staged in psychodrama. At this stage, the feedback and comments of the manager regarding the process are also very important. ${ }^{9}$ The content of the sessions is as follows:

Session 1: Meeting, Session 2: Exploring emotions, Session 3: What is my anxiety? What it looks like?, Session 4: Confronting anxiety and trust relationship in communication, 5: Understanding and accepting emotions, Session 6: What is empathy?, Session 7: Empathic communication and awareness, Session 8: Empathy with disabled people, Session 9: Empathy and trust relationship in communication, Session 10: Closure and farewell. 


\section{Data Collection Tools}

\section{Sociodemographic Information form}

The form, which consists of questions that enqure the demographic information about the volunteers and their family, was prepared by the researchers and filled in by the volunteers themselves.

\section{SAS-A}

This scale, which was originally known as the Social Anxiety scale for children-revised, was adapted to Turkish by Aydin et al. ${ }^{21}$. The original scale consisted of a total number of 22 items. Its Turkish version consists of a total of 18 items in addition to 4 items concerning different subjects such as 'I like to read books', and 'I enjoy doing sports' (items 2, 7, 11 and 16). The SAS-A consists of three subscales containing 18 items. In order to determine the validity of the scale, the principal component factor analysis was applied according to the varimax rotation method. As a result of the structural factor analysis, three factors explaining $48 \%$ of the total variance were found. These three factors were named as fear of negative evaluation (FNE), social avoidance and feeling of restlessness in general social situations (SARGS) and social avoidance and restlessness in new situations (SARNS). A five-point Likert-type rating (never, rarely, occasionally, usually and always) was used in responses to the items of the scale and expressed with scores ranging from 1 to 5 . Participants were asked to mark the intensity of the emotion they were experiencing, and stated in the items. Total score and subscale scores were obtained. The highest score obtained from the scale was 90 and the lowest score was 18. The high scores of the scale reflected high level of social anxiety. In the adaptation study, Aydın et al. ${ }^{21}$ calculated Cronbachs alpha internal consistency coefficients for the whole scale and its subdimensions in order to determine the reliability level of the scale. The reliability coefficients were 0.88 for the whole scale, 0.83 for the FNE, 0.68 for the SARGS and 0.71 for the SARNS. According to the data obtained from the sample group of this research, Cronbach's alpha internal consistency reliability coefficient values were calculated as 0.918 for the whole scale, 0.866 for the FNE, 0.845 for the SARGS and 0.720 for the SARNS subdimensions.

\section{Ka-Si Empathic Tendency scale-adolescent}

The Ka-Si Empathic Tendency scale for children and adolescents was developed by Kaya and Siyez ${ }^{22}$ in 2010 to determine the empathic tendencies of children. It consists of two factors: emotional empathy (10 items) and cognitive empathy (7 items). The Ka-Si Empathic Tendency scale-adolescent form was arranged in four grades: (1) Not at all suitable for me, (2) A slightly suitable for me, (3) Very suitable for me and (4) Totally suitable for me. The lowest and highest scores obtained from the emotional empathy (10 vs 40 pts), the cognitive empathy (7 vs 28 pts) and the empathic tendency ( 17 vs 68 pts) subdimension scores were indicated. The higher the scores, the more the decrease in empathic tendency. In the studies related to the construct validity of the adolescent form of the Ka-Si Empathic Tendency scale for children and adolescents, first factor analysis was performed one by one for each grade level, then the data of
6-12. Grades were combined and subsequently factor analysis was repeated.

The factor loadings of the 10 items in the emotional empathy subdimension ranged from 0.49 to 0.66 point; their correlations with the total subscale scores ranged from 0.51 to 0.83 , and the correlations with scores from the Entire scale 0.47 to 0.70 . As a result of the studies conducted for the reliability of the Empathic Tendency scale-adolescent form, Cronbach's alpha coefficient, which showed internal consistency, was 0.87 for the whole scale, 0.82 for emotional empathy, and 0.82 for cognitive empathy subdimensions. The test-retest reliability coefficient of the scale was found to be 0.75 for the whole scale, 0.73 for the emotional empathy and 0.69 for the cognitive empathy subdimensions. ${ }^{22}$

\section{Ethical Aspect of the Research}

For this study, ethics committee's approval was received from TR Ministry of Health, The Provincial Directorate of Health, Taksim Training and Research Hospital Clinical Research Ethics Committee (no: 82). The institutional permission was obtained from the relevant training and research hospital. Written informed consent was obtained from the children and their parents who agreed to participate in the study. In the study, the principles of providing informed consent, protection of confidentiality and non-harm/utility were taken into consideration.

\section{Statistical Analysis}

SPSS 11.5 statistical program was used for data analysis. Data were analysed by descriptive analysis, Kolmogorov-Smirnov test, Mann-Whitney U test and Kruskal-Wallis test.

\section{Limitations of the Study}

The limitation of the research was that the research was carried out in a small sample group and cross-sectionally.

\section{Result}

\section{Sociodemographic Characteristics}

Patients included in our study were in the age of $13(n=3$; $33.3 \%), 14(\mathrm{n}=2 ; 22.2 \%), 15(\mathrm{n}=2 ; 22.2 \%), 16(\mathrm{n}=1 ; 11.1 \%)$ and $17(n=1 ; 11.1 \%)$ years. The mean age of the patients was $14.4 \pm 1.42$ years. Out of the total, $55.6 \%$ were female and $44.4 \%$ were male students.

When the total scores of the Empathic Tendency for Adolescents scale were examined, there was no statistically significant difference in the change of score before and after the psychodrama treatment. Although the scores obtained from the Adolescent scale of empathic tendency increased after psychodrama, this change was not statistically significant. Based on the results of the study, the scores tend to increase even if there is no statistically significant change (Table 1). When the total scores of the SAS-A were examined, it was found that there was a statistically significant difference in the change before and after psychodrama $\left(\mathrm{p}=0.029^{*}\right)$. The social anxiety scale scores of adolescents after psychodrama were 
statistically lower than those obtained before psychodrama (Table 2).

\section{Discussion}

In this research, which examined the effect of psychodrama on developing adolescents' empathy skills and reducing their social anxiety, statistical analysis and feedback of the members showed that the method was effective. In this study, no statistically significant differences were found in pre-psychodrama and post-psychodrama changes when total scores obtained from empathic tendencies for adolescents were analysed. Although the scores obtained from the Adolescent scale of empathic tendency increased after psychodrama, this change was not statistically significant. This result shows that psychodrama positively contributes to developing empathic skills. The studies in the literature support this study results. In her study with 23 undergraduate students, Dogan ${ }^{23}$ stated that the students in the experimental group increased their empathy and counselling skills and self-awareness. In the study by $\mathrm{Ozdag}^{24}$, he determined that psychodrama had a positive effect on students' empathic skills and stated that empathic skill levels of the experimental group increased compared to the control group. In a study, Dogan ${ }^{25}$ emphasised the role of psychodrama in developing healthy and emotional relationships and stated that the patients had benefited greatly from psychodrama sessions, improved their behavioral and emotional insights and developed empathy skills. In a study conducted by Bairn et al. ${ }^{26}$ using nine psychodrama methods to improve victim empathy in nine male individuals who had committed sexual crime in England, it was found that victim empathy levels increased significantly after the intervention (over 20 sessions). Ulupinar ${ }^{27}$ stated in his study that there was an improvement in self-evaluation, awareness, expressing feelings and thoughts, creativity, empathy and problemsolving skills. Kalkan and $\mathrm{Ozdel}^{28}$ found that empathic skills were developed in the study conducted by the elderly in the nursing home using psychodrama techniques. Similarly, Ozcan et al. ${ }^{29}$ stated in their study that the empathic tendency skills increased in their mean scores after psychodrama practice. In the study by Oflaz et al. ${ }^{30}$, nurses stated that psychodrama was helpful in self-recognition, understanding others' perspective, developing their ability to express their own feelings and ideas and connecting with their feelings and ideas. Apart from these, other study results also showed that psychodrama had a positive effect on empathy skills. ${ }^{31,32}$ Unlike these results, Kaner $^{33}$ did not find a significant difference in the emotional aspect of empathy in the psychodrama study, but in cognitive dimension.

Empathic tendency is defined as the potential of empathy in an individual's daily life. It constitutes the emotional dimension of empathy and is an innate personality trait. Empathic tendency requires attitude development and personality change rather than a development in skills or cognitive functions. Because of these characteristics, it is very difficult to change the emphatic tendency, and as a result of the research, it is thought that the absence of excessive change in empathic tendency scores may have resulted from these reasons. ${ }^{34,35}$

Social anxiety is included in the literature under the name of social anxiety. Findings obtained from the study were discussed accordingly. In this study, when the total scores obtained from the Social Anxiety scale were examined, a statistically significant difference was found between before and after psychodrama. There was a decrease in scale scores after psychodrama. According to these results, we can say that psychodrama is an effective method in reducing social anxiety in adolescents. These results are also compatible with the literature. Karatas ${ }^{13}$ in his study, in which adolescents constantly look at their anxiety levels with psychodrama practice, found significant difference between experimental and control groups. Purehsan and $\mathrm{Sae}^{36}$ studied the effect of cognitive behavioral group therapy on reducing social anxiety among university students. It was observed that there was a big difference in the pre-test and post-test values of the experimental group and the study was concluded that cognitive behavioral group therapy was effective in improving the symptoms of social anxiety disorder (SAD). In Turkey, scarce number of studies assessed the relationship between SAD and psychodrama. Dogan ${ }^{37}$ held 12 sessions of psychodrama on 21 graduate students and found that psychodrama

Table 1. The level of empathy in adolescents before and after psychodrama sessions

\begin{tabular}{llllllll}
\hline & \multicolumn{2}{c}{ Before psychodrama } & \multicolumn{2}{c}{ After psychodrama } & Difference & p \\
\cline { 2 - 7 } & $\mathbf{X} \pm$ SD & $\begin{array}{l}\text { Med } \\
\text { (min-max) }\end{array}$ & $\mathbf{X} \pm$ SD & $\begin{array}{l}\text { Med } \\
\text { (min-max) }\end{array}$ & X \pm SD & $\begin{array}{l}\text { Med } \\
\text { (min-max) }\end{array}$ \\
\hline Empathic Tendency scale & $51.56 \pm 4.67$ & $52(46-58)$ & $56.67 \pm 10.21$ & $61(38-65)$ & $-5.11 \pm 7.69$ & $-8(-14-10)$ & $0.081(t=-1.994)$ \\
\hline
\end{tabular}

Mann-Whitney U, Kruskal-Wallis test, SD: Standard deviation, min= Minimum, max: Maksimum

Table 2. Social anxiety level of the adolescents before and after psychodrama

\begin{tabular}{|c|c|c|c|c|c|c|c|}
\hline & \multicolumn{2}{|c|}{$\begin{array}{l}\text { Before } \\
\text { psychodrama }\end{array}$} & \multicolumn{2}{|c|}{$\begin{array}{l}\text { After } \\
\text { psychodrama }\end{array}$} & \multicolumn{2}{|l|}{ Difference } & \multirow[t]{2}{*}{$\mathbf{p}$} \\
\hline & $\mathbf{X} \pm \mathbf{S D}$ & $\begin{array}{l}\text { Med } \\
\text { (min-max) }\end{array}$ & $\mathbf{X} \pm \mathbf{S D}$ & $\begin{array}{l}\text { Med } \\
\text { (min-max) }\end{array}$ & $\mathbf{X} \pm \mathbf{S D}$ & $\begin{array}{l}\text { Med } \\
\text { (min-max) }\end{array}$ & \\
\hline Social Anxiety scale & $61.67 \pm 16.81$ & $59(36-86)$ & $48.78+8.12$ & $49(35-63)$ & $12.89 \pm 14.52$ & $11(6-33)$ & $0.029^{*}(t=-2.663)$ \\
\hline
\end{tabular}

*p<0.05, Mann-Whitney U, Kruskal-Wallis test, SD: Standard deviation, min= Minimum, max: Maksimum 
was effective in reducing anxiety levels of students. Although Uneri et al. ${ }^{19}$ examined the use of psychodrama in adolescents with SAD, since the objectives of their study were investigation of characteristics of psychodrama group treatment applications in adolescents, the strengths and weaknesses of the applications and the creation of psychodrama group model for adolescents, any statistical data could not be derived from this study for comparison. When we look at the literature, it is difficult to come across a study where social anxiety or SAD and psychodrama were dealth in combination. In the study, Dehnavi et al. ${ }^{38}$ found that there was a significant decrease in the social anxiety symptoms among the adolescents in the experimental group compared to the control group in which male adolescents measured the effectiveness of psychodrama in reducing SAD. Akinsola and Udoka ${ }^{39}$ found that psychodrama was effective in reducing anxiety levels in children. Oguzhanoglu et al. ${ }^{40}$ stated that there was a decrease in social anxiety scores after the combined use of drug and psychodramatic group therapy. Görkem and Tüccar ${ }^{41}$ found a decrease in anxiety levels of university students after 13 sessions of psychodrama.

In the study where Abeditehrani et al.$^{42}$ used cognitive behavioral therapy and psychodrama together, they found a decrease in the symptoms of social anxiety. In another study where the effect of psychodrama on reducing anxiety in male schizophrenia patients was investigated, it was observed that psychodrama reduced anxiety symptoms in them. ${ }^{43}$

The results of the study by Pratama et al. ${ }^{44}$ are quite similar to the results of this study. Pratama et al ${ }^{44}$ found that psychodrama and sociodrama techniques are effective in developing emotional intelligence in their group counselling study. Their study states that individuals trust themselves to speak in front of others and have empathy to care more about the situation of others.

\section{Conclusion}

As a result of group therapy using psychodrama technique with adolescents, a significant decrease in the social anxiety levels of the participants and increase in their empathy scores were found when they were examined one by one. It was thought that the change in the empathic approach could be measured better by increasing the number of group members, and more comprehensive results could be provided with a registration method compatible with the qualitative analysis. Psychodrama is a psychotherapy method that exerts beneficial effects in solving problems peculiar to adolescence, concerns of success, social anxiety, problem solving in general and development of empathic skills. Since in our country inadequate number of studies have been performed in this field, primarily qualified relevant studies should be performed.

\section{Ethics}

Ethics Committee Approval: For this study, ethics committee's approval was received from TR Ministry of Health, The Provincial Directorate of Health, Taksim Training and Research Hospital Clinical Research Ethics Committee (no: 82).
Informed Consent: Written informed consent was obtained from the children and their parents who agreed to participate in the study.

Peer-review: Internally peer-reviewed.

\section{Authorship Contributions}

Concept: Ç.Ş., E.Y.Y., E.A., E.A.Y., Design: Ç.Ş., E.Y.Y., E.A., E.A.Y., Data Collection or Processing: Ç.Ş., Analysis or Interpretation: Ç.Ş., E.A., Literature Search: Ç.Ş., E.A., Writing: Ç.Ş., E.A.

Conflict of Interest: No conflict of interest was declared by the authors.

Financial Disclosure: The authors declared that this study received no financial support.

\section{References}

1. Wittchen HU. The many faces of social anxiety disorder. International Clinical Psychopharmacology. 2000;(15 Suppl 1):7-12.

2. Teachman BA, Allen JP. Development of Social anxiety: Social Interaction Predictors of Implicit and Explicity Fear of Negative Evaluation. Journal of Abnormal Child Psychology. 2007;35:6378.

3. Kashdan TB, Herbert JD. Social anxiety disorder in childhood and adolescence: current status and future directions. Clin Child Fam Psychol Rev. 2001;4:37-61.

4. La Greca AM. Friend of foes? Peer influences on anxiety among children and adolescents. In: Silverman WK, Treffers. Anxiety disorders in children and adolescents; research, assessment, and intervation. San Diego-California; Academic press Inc; 2001:159186.

5. Jackson T. Protective self-presentation, sources of socialization, and loneliness among Australian adolescents and young adults. Personality and Individual Differences. 2007;43:1552-1562.

6. Rosen LM, Sheridan AM, Sambrook AK, Dennison JM, Jenness JM, Askren KM, Meltzoff NA McLaughlin AK. Salience network response to changes in emotional expressions of others is heightened during early adolescence: relevance for social functioning. Developmental Science. 2018;21:e12571.

7. Kessler RC, Chiu WT, Demler O, Merikangas KR, Walters EE. Prevalence, severity, and comorbidity of 12-month DSM-IV disorders in the National Comorbidity Survey Replication. Arch Gen Psychiatry. 2005;62:617-627.

8. Evren C. Social anxiety disorder and alcohol use disorders. Current Approaches in Psychiatry. 2010;2:473-515.

9. Dökmen U. Sociometry and psychodrama. Istanbul: Sistem Publishing (4th ed). 2003;1-122.

10. Ozbek A, Leutz G. Stage interaction in psychodrama group psychotherapy. Ankara: Abdülkadir Ozbek Psychodrama Institute Publications; 2003.

11. Kellermann PF. Focus on psychodrama: The therapeutic aspects of psychodrama. London: Jessica Kingsley Publishers Ltd. 1992.

12. Hoag JM, Burlingame MG. Evaluating the effectiveness oş child and adolescent group treatment: A meta-analytic review. J Clin Child Psychol. 1997;26:234-246.

13. Karatas Z, Gökçakan Z. Investigation of the effect of group practices using psychodrama techniques on reducing aggression in adolescents. Turkish Journal of Psychiatry. 2009;20:357-366.

14. Gökler B, Gökler I. Group psychotherapy and psychodrama in children and adolescents. Aysev AA, Taner IY, eds. Child and Adolescent Mental Health and Diseases. Istanbul; Golden Print;2007:893-915. 
15. Cakır V. Interactive TV and Interactive Drama. New Communication Environments and Interaction International Conference / 1-3 November 2006. https://www.researchgate.net/ publication/292982267_ETKILESIMLI_TV_VE_ETKILESIMLI_ DRAMA

16. Decety J, Ackson PL. The functional architecture of human empathy. Behavioral and Cognitive Neuroscience Reviews. 2004;3:71-100.

17. Tarhan N. Community Psychology: From Social Schizophrenia to Social Empathy, Istanbul; Timas Publishing; 2010.

18. Dökmen U. Communication conflicts and empathy in art and daily life.(5th ed). Istanbul; Remzi Bookstore; 2009:1-392.

19. Uneri OS, Akgün EY, Tanıdır C, Aytemiz T. The Use of Psychodrama in Adolescents with Social Anxiety Disorder. Anatolian Journal of Psychiatry. 2016;17:347-353.

20. Altınay D. Psychodrama group psychotherapy handbook. Istanbul; Sistem Publishing; 2003.

21. Aydın A, Sütcü TS, Sorias O. Examining the validity and reliability of the Social Anxiety Scale for Adolescents. Journal of Child and Youth Mental Health. 2007;14:79-89.

22. Kaya A, Siyez DM. KA-Sİ Empathic Tendency Scale for Children and Adolescents: Development, validity and reliability study. Education and Science Journal. 2010;35:110-125.

23. Dogan T. The effects of the psychodrama in instilling empathy and self-awareness: A pilot study. PsyCh Journal. 2018;7:227-238.

24. Ozdag S. Effects of Psychodrama Groups on Nursing School Students' Self-Esteem, Assertive Behavior, Empathic Tendency and Empathic Skill Levels. Unpublished Doctoral dissertation. Hacettepe University Institute of Health Sciences;Ankara; 1999:132.

25. Dogan T. The Role of Psychodrama in Developing Healthy Emotional Relations: A Case Study. Turkish Psychological Counseling and Guidance Journal. 2012;4:49-60.

26. Bairn C, Allam J, Eames T, Dunford S, Hunt S. The use of psychodrama to enhance victim empathy in sex offenders: An evaluation, Journal of Sexual Aggression. 1999;4:4-14.

27. Ulupinar S. The effect of psychodrama practice on nursing students' problem solving skills. Anatolian Journal of Psychiatry. 2014;15:55 62.

28. Kalkan NO, Ozdel O. A psychodrama study on old-age, nursing home and life journeys. Turkish Psychiatry Journal. 2005;16:124-132.

29. Ozcan KN, Bilgin H, Eracan N. The Use of Expressive Methods for Developing Empathic Skills. Issues in Mental Health Nursing. 2011;32:131-136.

30. Oflaz F, Meric M, Yuksel C, Ozcan CT. Psychodrama: An innovative way of improving self-awareness of nurses. Journal of Psychiatric and Mental Health Nursing. 2011;18:569-575.
31. Sangappa SB, Tekian A. Communication skills course in an Indian undergraduate dental curriculum: A randomized controlled trial. Journal of Dental Education. 2013;77:1092-1098.

32. Kesten KS. Role-play using SBAR technique to improve observed communication skills in senior nursing students. The Journal of Nursing Education. 2011;50:79-87.

33. Kaner S. Effect of psychodrama and reality therapy on the self concept and empathy levels of the young offenders. Psychiatry Psychology Psychopharmacology Journal. 1993;1:165-172.

34. Tutuk A, Al D, Dogan S. Investigation of Communication Skills and Empathy Levels of Nursing Students. Cumhuriyet University School of Nursing Journal. 2002;6:36-41.

35. Mete S, Gercek E. Investigation of Empathic Tendency and Skills of Nursing Students Studying with Problem Based Learning Management. Cumhuriyet University School of Nursing Journal. 2005;9:1-7.

36. Purehsan S, Sae O. Effectiveness Of Cognitive-Behavioral Group Therapy (CBGT) On Reduction Of Social Phobia". Procedia Social and Behavioral Sciences. 2010;1694-1697.

37. Dogan T. The effects of psychodrama on young adults' attachment styles. The Arts in Psychotherapy. 2010;37:112-119.

38. Dehnavi S, Hadadi Z, Jelveh M, Safaryazdi Z, Panahi P. The Effectiveness of Psychodrama in the Reduction of Social Anxiety Disorder among Male Adolescents. The Neuroscience Journal of Shefaye Khatam. 2014;2:52-53.

39. Akinsola FE, Udoka AP. Parental Influence on Social Anxiety in Children and Adolescents: Its Assessment and Management Using Psychodrama. Psychology. 2013;4:246-253.

40. Oguzhanoglu KN, Bayraktutan M, Varma SG, Ugurlu TT. Sosyal anksiyete bozukluğunda aleksitimi ve sempatik deri yanıtları üzerine ilaç ve psikodrama grup terapisinin etkileri. Klinik Psikiyatri Dergisi. 2019;22:452-462.

41. Görkem A, Tüccar L. The effect of psychodrama on university students' anxiety levels. Turkish Studies. 2018;13:599-620.

42. Abeditehrani H, Dijka C, Toghchi SM, Arntz A. Integrating Cognitive Behavioral Group Therapy and Psychodrama for Social Anxiety Disorder: An Intervention Description and an Uncontrolled Pilot Trial.Clinical Psychology in Europe. 2020;2:1-21.

43. Tehrani AH. Effectiveness of Psychodrama on Reduction of Anxiety among Male Schizophrenic Patients. The Neuroscience Journal of Shefaye Khatam. 2014;2:64.

44. Pratama SY, Wibowo EM, Awalya M. Group Counseling with Psychodrama and Sociodrama Techniques to Improve Emotional Intelligence. 2019;8:79-85. 